\title{
The Risk of Cardiac-related Mortality in Stage IIIA- N2 Non-small Cell Lung Cancer: Analysis of the Surveillance, Epidemiology, and End Results Database
}

\section{Xin Sun}

Chinese Academy of Medical Sciences and Peking Union Medical College https://orcid.org/0000-00030336-4769

\section{Yu Men}

Chinese Academy of Medical Sciences and Peking Union Medical College Jianyang Wang

Chinese Academy of Medical Sciences and Peking Union Medical College

\section{Yongxing Bao}

Chinese Academy of Medical Sciences and Peking Union Medical College

\section{Xu Yang}

Chinese Academy of Medical Sciences and Peking Union Medical College

\section{Maoyuan Zhao}

Chinese Academy of Medical Sciences and Peking Union Medical College

\section{Shuang Sun}

Chinese Academy of Medical Sciences and Peking Union Medical College

\section{Meng Yuan}

Chinese Academy of Medical Sciences and Peking Union Medical College

\section{Zeliang Ma}

Chinese Academy of Medical Sciences and Peking Union Medical College

\section{Zhouguang Hui ( $\square$ drhuizg@163.com )}

Chinese Academy of Medical Sciences and Peking Union Medical College https://orcid.org/0000-00027189-4692

\section{Research}

Keywords: non-small cell lung cancer, stage $₫ \mathrm{~A}-\mathrm{N} 2$, postoperative radiotherapy, cardiac-related mortality

Posted Date: December 22nd, 2020

DOI: https://doi.org/10.21203/rs.3.rs-131838/v1 
License: (c) (i) This work is licensed under a Creative Commons Attribution 4.0 International License. Read Full License 


\section{Abstract}

Background: We aimed to investigate the association between postoperative radiotherapy (PORT) and cardiac-related mortality for patients with $₫ A-N 2$ non-small cell lung cancer (NSCLC) by the Surveillance, Epidemiology, and End Results (SEER) database.

Methods: The United States (US) population based SEER database were queried for cardiac-related mortality among patients with $\triangle A-N 2$ NSCLC. Cardiac-related mortality was compared between PORT and Non-PORT group. Accounting for mortality from other causes, Gray's test compared cumulative incidences of cardiac-related mortality between both groups. Univariate and multivariate analysis were performed using the competing risk model.

Results: From 1988 to 2016,7290 patients met the inclusion criteria: 3386 patients treated with PORT and 3904 patients treated with Non-PORT. The 5-year overall incidence of cardiac-related mortality was $3.01 \%$ in PORT group and $3.26 \%$ in Non-PORT group. Older age, male sex, squamous cell lung cancer, earlier year of diagnosis and earlier T stage were independent adverse factors for cardiac-related mortality. However, PORT use wasn't associated with an increase in the hazard for cardiac-related mortality (subdistribution hazard ratio [SHR] $=0.99,95 \%$ confidence interval [95\% Cl], 0.78-1.24, $p=0.91$ ). When evaluating cardiac-related mortality in each time period, the overall incidence of cardiac-related mortality was decreased over time. There were no statistically significant differences based on PORT use in all time periods.

Conclusions: With a median follow-up of 25 months, no significant differences were found in cardiacrelated mortality between PORT and Non-PORT for $\triangle A-N 2$ NSCLC patients.

\section{Background}

Chest radiotherapy plays an important role in the treatment of breast cancer, Hodgkin's lymphoma, lung cancer and other malignancies, which can also cause cardiovascular events and deaths. Cardiac-related mortality has long been recognized in patients with breast cancer or Hodgkin lymphoma[1-5], with a typical latency period of more than a decade. And the radiation-associated cardiac risk appears to increase with time after exposure ${ }^{5}$. As the life expectancy of non-small cell lung cancer (NSCLC) continues to rise, cardiac-related mortality is apparent in long-term cancer survivors of NSCLC. Several studies report increased cardiac events and deaths after definitive radiotherapy for locally-advanced NSCLC (LA-NSCLC)[6-9]. Recently, the Radiation Therapy Oncology Group (RTOG) 0617 (A Randomized Phase III trial) reported that heart radiation dose was associated with worse overall survival with a median follow-up of 2 years, suggesting a contribution of radiation-induced cardiac mortality relatively soon after treatment[10]. Postoperative radiotherapy (PORT) has been posited as an important component of the comprehensive treatment of operable $\triangle A-N 2$ NSCLC[11]. However, evidence for cardiacrelated mortality after Postoperative radiotherapy (PORT) is more limited in recent years. Given the parallels in definitive radiotherapy of LA-NSCLC, cardiac-related mortality of PORT gain importance in $\triangle A$ - 
N2 NSCLC, especially with contemporary treatment modality. In the present study, we assessed the effect of PORT on cardiac-related mortality in $\triangle A-N 2$ NSCLC patients using a large population-based database, and stratified these patients over time intervals to assess the cardiac-related mortality by treatment era.

\section{Methods}

\section{National Cancer Institute's Surveillance, Epidemiology, and End Results (SEER) Database}

The SEER database is maintained at the National Cancer Institute, funded by the National Cancer Institute, collects data from approximately $28 \%$ of the population of the United States (US), which contains patient demographics, clinicopathological features, first course of treatment, and follow-up for vital status. The SEER database is a worldwide public database, and we have permission to access the SEER database (authorization code 12201-Nov2019).

\section{Case selection (Patients, covariates, and treatment information)}

Our study population was chosen from the SEER database (SEER 18 Regs Custom data [with additional treatment field], Nov 2018 Sub [1975-2016 varying]). We used the SEER*Stat software (version 8.3.6.1) for data extraction. We identified our patient population by querying "Site recode ICD-0-3/WHO 2008" with the term "Lung and Bronchus" as the primary site. The following NSCLC histologic types were included: adenocarcinoma (International Classification of Diseased for Oncology- 3 [ICD-0-3] codes $8140-8141,8143,8147,8480,8481,8260,8550,8570-8576,8255)$, squamous cell (8070-8078), broncho-alveolar adenocarcinoma (8250-8254), adenosquamous (8560, 8562), 8046 (NSCLC, NOS) or large cell (8012-8014). We chose to examine the period from 1988 to 2016, because these years corresponded to the start of TNM staging by SEER and the most recent available patient information, respectively. Patients diagnosed with NSCLC between 1988 and 2016 who met the following criteria were included: 1. Patients underwent either a lobectomy or pneumonectomy; 2. Patients diagnosed with T13N2M0 (Stage $₫ A-N 2$, American Joint Committee on Cancer 3rd Edition [for patients diagnosed from 1988-2003], American Joint Committee on Cancer 6th Edition [for patients diagnosed from 2004-2009] and American Joint Committee on Cancer 7th Edition [for patients diagnosed from 2010-2016]). And the Exclusion criteria were bilateral tumors or unknown laterality, main bronchus tumors or overlapping lesion or unknown lobe, without postoperative external-beam irradiation or unknown, multiple primary, and having survived for less than 3 months. Two cohorts were then created: (I) patients who received postoperative radiotherapy (PORT) as part of their initial therapy; and (II) those who did not receive postoperative radiotherapy (Non-PORT) as part of their initial therapy. The work flow is shown in Fig. 1.

For each case, we requested the following information: age, sex, race, year of diagnosis, histology, tumor laterality (right vs left), subsite location (upper lobe, middle lobe, lower lobe), T stage, surgical procedure (lobectomy vs pneumonectomy), use of radiotherapy, presumed survival in months, vital status, and 
cause of death. Cardiac-related mortality information was obtained from cause of death data extracted from the SEER database.

\section{Statistical analysis}

We compared the differences in demographics, clinicopathology, and treatment characteristics among patients who did and did not receive PORT by chi-square test. The cardiac-related mortality rate during the study period were graphed by the initial year of diagnosis. We divided patients by the year of diagnosis of 1988-1997, 1998-2007, 2008-2016. Cumulative incidence curves of cardiac-related mortality (from the date of diagnosis) were constructed for PORT versus non-PORT, accounting for mortality from other causes. The underlying hazards were statistically compared using Gray's test. Univariate and multivariate analysis were performed using the competing risks regression (Fine and Gary method[12]) to analyze the risk factors for cardiac-related mortality including age, sex, race, histology, tumor laterality, subsite location, T stage, surgical procedure, use of radiotherapy by assessment of the subdistribution hazard ratios (SHRs) and their corresponding 95\% confidence interval (95\% Cl). A P-value of less than 0.05 was set as the threshold for significance. All analyses were performed with the software of R Version 3.6.2.

\section{Results}

We identified 7290 patients who met the criteria described above, including 3386 (46.4\%) patients with PORT and 3905 (53.6\%) patients with Non-PORT. The median age of the entire cohort was 66 years (range, 18-95 years). A comparison of demographic, clinicopathologic and treatment factors were presented in Table 1. The distribution of age $(P<0.001)$, year of diagnosis $(P<0.001)$, histological type $(P$ $=0.039)$, subsite location $(P=0.002)$, and chemotherapy status $(P=0.016)$ by comparing PORT with NonPORT reached statistical significance. The median follow-up was 25 months (range, 3-320 months). A total of 308 patients died of cardiac-related diseases. 145 and 163 patients died of cardiac-related diseases in PORT and Non-PORT group, respectively. 
Table 1

Patient Characteristics

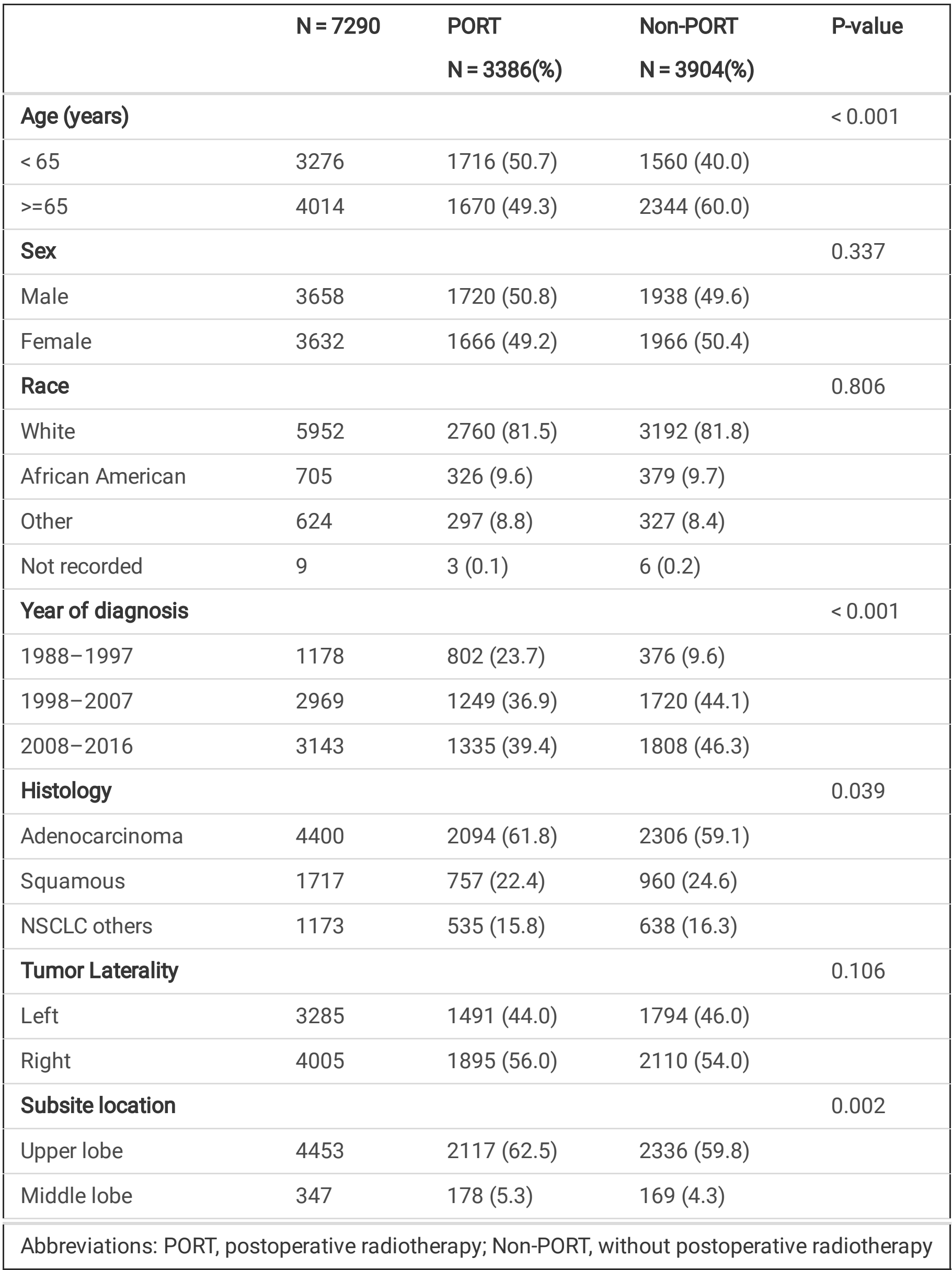




\begin{tabular}{|c|c|c|c|c|}
\hline & $N=7290$ & $\begin{array}{l}\text { PORT } \\
\mathrm{N}=3386(\%)\end{array}$ & $\begin{array}{l}\text { Non-PORT } \\
\mathrm{N}=3904(\%)\end{array}$ & P-value \\
\hline Lower lobe & 2490 & $1091(32.2)$ & $1399(35.8)$ & \\
\hline T stage & & & & 0.09 \\
\hline T1 & 2009 & $924(27.3)$ & $1085(27.8)$ & \\
\hline $\mathrm{T} 2$ & 4391 & 2018 (59.6) & $2373(60.8)$ & \\
\hline T3 & 890 & $444(13.1)$ & $446(11.4)$ & \\
\hline Surgical procedure & & & & 0.247 \\
\hline Lobectomy & 6406 & 2992 (88.4) & 3414 (87.4) & \\
\hline Pneumonectomy & 884 & $394(11.6)$ & $490(12.6)$ & \\
\hline
\end{tabular}

Figure 2 presents the cardiac-related mortality curves stratified by PORT use. The 5-year overall cardiacrelated mortality was $3.01 \%$ in PORT group compared with $3.26 \%$ in Non-PORT group. There were no significant differences $(p=0.49)$ between PORT and Non-PORT (Fig. 2A). The 5-year overall cardiacrelated mortality for PORT versus Non-PORT patients in each time interval was as follows: $3.62 \% \mathrm{vs}$. $3.99 \%$ (1988-1997), $3.37 \%$ vs. $3.39 \%$ (1998-2007) and $2.21 \%$ vs. $2.81 \%$ (2008-2016), respectively. When evaluating cardiac-related mortality in each of the time periods (Figs. 2B-D), the overall incidence of cardiac-related mortality was decreased over time. There were no statistically significant differences based on PORT use in all time periods.

Table 2 shows results of univariate and multivariate models, accounting for several confounding variables and mortality from other causes. On univariate analysis, cardiac-related mortality events were significantly associated with age $>=65(p<0.001)$, male patients $(p<0.001)$, diagnosis year of $1988-$ $1997(p<0.001)$, squamous cell carcinoma $(p<0.001)$, and T1 stage $(p<0.001)$. On multivariate analysis, age, sex, year of diagnosis, histology, and T stage remained significantly associated with cardiac-related mortality. On univariate and multivariate analysis, PORT wasn't associated with an increased risk for cardiac-related mortality (univariate: $\mathrm{SHR}=1.0,95 \% \mathrm{Cl}, 0.97-1.24, \mathrm{p}=0.97$; multivariate: $\mathrm{SHR}=0.99,95 \%$ $\mathrm{Cl}, 0.78-1.24, \mathrm{p}=0.91)$. 
Table 2

Univariate and Multivariate Analysis of Cardiac-Related Morality Using Fine and Gray Hazard for Patients with Resected IIIA-N2 NSCLC

\begin{tabular}{|c|c|c|c|c|c|c|}
\hline & \multirow{2}{*}{\multicolumn{3}{|c|}{$\begin{array}{l}\text { Fine and Gray Hazard of Cardiac } \\
\text { Related Death } \\
\text { (Univariate) }\end{array}$}} & \multirow{2}{*}{\multicolumn{3}{|c|}{$\begin{array}{l}\text { Fine and Gray Hazard of Cardiac Related } \\
\text { Death (Multivariate) }\end{array}$}} \\
\hline & & & & & & \\
\hline & SHR & $95 \% \mathrm{Cl}$ & p-value & SHR & $95 \% \mathrm{Cl}$ & $p$-value \\
\hline \multicolumn{7}{|l|}{ Age (years) } \\
\hline$<65$ & Ref & & & Ref & & \\
\hline$>=65$ & 1.69 & $1.34-2.15$ & $<0.001$ & 1.67 & $1.32-2.12$ & $<0.001$ \\
\hline \multicolumn{7}{|l|}{ Sex } \\
\hline Male & Ref & & & Ref & & \\
\hline Female & 0.65 & $0.52-0.82$ & $<0.001$ & 0.71 & $0.57-0.90$ & $<0.001$ \\
\hline \multicolumn{7}{|l|}{ Race } \\
\hline White & Ref & & & Ref & & \\
\hline $\begin{array}{l}\text { African } \\
\text { American }\end{array}$ & 1.31 & $0.93-1.85$ & 0.12 & 0.35 & $0.96-1.90$ & 0.08 \\
\hline Others & 0.43 & $0.24-0.76$ & $<0.001$ & 0.50 & $0.28-0.89$ & 0.02 \\
\hline \multicolumn{7}{|l|}{$\begin{array}{l}\text { Year of } \\
\text { diagnosis }\end{array}$} \\
\hline 1988-1997 & Ref & & & Ref & & \\
\hline 1998-2007 & 1.19 & $0.95-1.49$ & 0.13 & 0.75 & $0.57-0.98$ & 0.03 \\
\hline $2008-2016$ & 0.51 & $0.39-0.67$ & $<0.001$ & 0.46 & $0.33-0.64$ & $<0.001$ \\
\hline \multicolumn{7}{|l|}{ Histology } \\
\hline Adenocarcinoma & Ref & & & Ref & & \\
\hline Squamous & 1.97 & $1.57-2.48$ & $<0.001$ & 1.86 & $1.44-2.42$ & $<0.001$ \\
\hline NSCLC others & 1.00 & $0.75-1.35$ & 0.98 & 1.22 & $0.89-1.67$ & 0.23 \\
\hline \multicolumn{7}{|l|}{ Tumor Laterality } \\
\hline Left & Ref & & & & & \\
\hline Right & 0.88 & $0.70-1.09$ & 0.24 & 0.85 & $0.67-1.07$ & 0.16 \\
\hline \multicolumn{7}{|l|}{ Subsite location } \\
\hline Upper lobe & Ref & & & Ref & & \\
\hline
\end{tabular}




\section{Fine and Gray Hazard of Cardiac Related Death}

\section{(Univariate)}

Fine and Gray Hazard of Cardiac Related Death (Multivariate)

\begin{tabular}{|lcccccc|}
\hline Middle lobe & 1.02 & $0.61-1.71$ & 0.93 & 1.18 & $0.69-2.02$ & 0.55 \\
\hline Lower lobe & 1.16 & $0.92-1.47$ & 0.20 & 1.15 & $0.90-1.46$ & 0.27 \\
\hline T stage & & & & & & \\
T1 & Ref & & & Ref & & \\
T2 & 1.20 & $0.95-1.51$ & 0.13 & 0.85 & $0.65-1.10$ & 0.21 \\
T3 & 0.42 & $0.25-0.69$ & $<0.001$ & 0.39 & $0.23-1.66$ & $<0.001$ \\
$\begin{array}{l}\text { Surgical } \\
\text { procedure }\end{array}$ & & & & & & \\
\hline Lobectomy & Ref & & & Ref & & \\
\hline $\begin{array}{l}\text { Pneumonectomy } \\
\text { Radiation }\end{array}$ & 1.24 & $0.91-1.69$ & 0.16 & 1.02 & $0.74-1.42$ & 0.89 \\
\hline Non-PORT & Ref & & & & & 0.91 \\
\hline PORT & 1.00 & $0.80-1.24$ & 0.97 & 0.99 & $0.78-1.24$ & \\
\hline
\end{tabular}

\section{Discussion}

The effect of PORT on cardiac-related mortality is critical due to inadequately capturing the cardiacrelated mortality risks in recent years. Our population-based analysis offers a holistic update on the cardiac-related mortality risks in $\triangle A-N 2$ NSCLC patients who underwent PORT. To our knowledge, this is the first study concentrating on the incidence and trends of competing risk cardiac-related mortality in $\square \mathrm{A}$ N2 NSCLC patients with long observation, and the results show that cardiac-related mortality has no association with PORT use between 1988 and 2016. And the incidence of cardiac-related modality has decreased over time.

Previous studies have demonstrated a benefit in local-regional control by using PORT but whether PORT could improve overall survival remains controversial[13-18]. The insignificant survival benefits with PORT could partially be explained by the early and late toxicities, including radiation esophagitis, radiation pneumonitis and radiation induced heart diseases. And cardiac-related mortality is one of the detrimental effect of PORT on survival. Several studies have reported increased cardiac-related mortality with PORT after surgery for stage I to $\triangle$ NSCLC[19-21]. Lally et al[20] conducted the risk of cardiac-related mortality associated with PORT of resected NSCLC patients. It was demonstrated that PORT was associated with an increase in cardiac-related mortality independent of the expected effects of age, sex, and race between 1983 and 1988 by using SEER database. However, significant differences exist 
between Lally et al[20] and our study, given the substantial heterogeneity in patient selection, year of diagnosis and method of statistics analysis. First, in the study by Lally et al[20], a mixture of patients with varying stages (stage I to III) of resected NSCLC were included. In contrast, our study concentrated on $\triangle A$ N2 NSCLC patients, representing a population that is most likely to benefit from PORT. Second, the recruitment of patients included in Lally et al[20] went from 1983 to 1988 comparing with 1988 to 2016 in our study. Lastly, compared the results of study by Lally et al[20], our study used competing risk model to avoid overestimate cumulative survival rate and incorrectly evaluate the effects of covariates on the hazard ratio to the occurrence of the cardiac-related death event. This guaranteed the result's reliability of our study.

Our study found an approximate $3 \%$ cardiac-related mortality rate at 5 years experienced by all patients with $\triangle A-N 2$ NSCLC who receive either PORT or Non-PORT. The insignificant difference of cardiac-related mortality observed between PORT and Non-PORT group in our study is probably due to the contemporary radiation techniques, limited volumes of radiation, suitable radiation doses and fraction sizes[22, 23]. Taken together, these factors likely decreased the volume of heart exposed to high dose radiation. Trials with contemporary radiation techniques demonstrated that there was no increase of death from intercurrent disease[24-28]. A serious of recently published non-randomized trials could not detect difference in cardiac-related mortality between patients receiving 3D-planned PORT group in comparison to Non-PORT group $[14,29,30]$. What's more, the advances in lung cancer treatment could also explain the decrease of cardiac-related mortality over time (1988-2016). The trends are consistent with the analysis of Lally et al[20] and Haque et al[9]. Lally et al[20] demonstrated the decrease of cardiac-related mortality in resected NSCLC (1983-1993), while Haque et al[9] illustrated that the incidence of cardiac-related mortality has decreased over time in LA-NSCLC (1988-2014).

On univariate and multivariate analysis, our study confirmed that patients of older age, male patients, squamous cell lung cancer, earlier year of diagnosis and earlier $\mathrm{T}$ stage were more likely to have higher rates of cardiac-related mortality. This may be explained by the baseline risks of these subgroups rather than any relation to radiotherapy[31,32]. This implies that patients with greater comorbidities or potential for longer survival may require extra attention to cardiac sparing[33]. Cardiac monitoring with imaging and routine involvement of cardiologist in the pre- and post-treatment care may be necessary for patients with cardiac-related mortality risk factor. Although there is no association between PORT use and cardiacrelated mortality, cardiovascular issues such as cardiomyopathy, arterial disease, hypertension, and vascular and metabolic issues could manifest during or after therapy due to PORT-related toxicities. And we still encourage clinical attentiveness to cardiac-sparing radiotherapy and emphasize overall health through management of early and late cardiac toxicities. With increasing life expectancy of $\triangle A-N 2$ NSCLC, further studies are needed in order to provide dosimetric correlates for cardiac toxicities, which is rarely reported in previous studies[34].

Several limitations should be acknowledged when interpreting our results. First, just as other studies derived from SEER database, our study is limited by the lack of important paramenters, such as the following: comorbid conditions, smoking history, chemotherapy utilization, radiation therapy dose, 
technique and target, which are potential confounders for our study. Second, there is an inherent weakness of selection bias in a population-based observational study. Third, the number of events was low, which limits the examination of multiple covariates.

These shortcomings notwithstanding, our study is still the largest retrospective study to address this important clinical question. What's more, the large cohort of population-based patients provides sufficient power to detect relatively small increases in cardiac-related mortality for $\triangle A-N 2$ NSCLC. We believe that PORT use is safe in $\triangle A-N 2$ NSCLC patients, without worrying about cardiac-related mortality.

\section{Conclusions}

In conclusion, this study characterizes the cardiac-related mortality by PORT use in patients with NSCLC. In all patients over the studied period, no significant differences were found in cardiac-related modality between PORT and Non-PORT group in $\triangle A-N 2$ NSCLC patients. The overall incidence of cardiac-related mortality was decreased over time. Although the association with PORT cannot be proven in our study, we still encourage attentiveness to early and late cardiac toxicities. And more researches are needed to find out the association between cardiac toxicities and PORT in $\triangle A-N 2$ NSCLC.

\section{Abbreviations}

NSCLC: Non-small cell lung cancer; LA-NSCLC: locally-advanced non-small cell lung cancer; PORT: Postoperative radiotherapy; SEER: Surveillance, epidemiology, and end results; Cl: Confidence interval; HR: Hazard ratio.

\section{Declarations}

\section{Acknowledgements}

Not applicable.

\section{Authors' contributions}

Xin Sun contributed to the conception, design of study, acquisition of data, quality control, data analysis and interpretation, statistical analysis, manuscript preparation, editing and review. Yu Men, Jianyang Wang, Yongxing Bao, Xu Yang, Maoyuan Zhao, Shuang Sun, Meng Yuan and Zeliang Ma contributed substantially to the acquisition of data, quality control of data and review. Zhouguang Hui contributed substantially to the conception of study, manuscript preparation, editing and review. All authors read and approved the final manuscript.

\section{Funding}


This study was supported by the National Key Research and Development Program (2017YFC1311000, 1311002), the Founding for Capital Clinical Special Application Research of China (Z171100001017114) and Beijing Hope Run Special Fund of Cancer Foundation of China (LC2016L03).

\section{Competing interests}

The authors declare that they have no competing interests.

\section{Availability of data and materials}

The datasets analyzed during the current study are available in SEER database using SEER ${ }^{\star S t a t}$ 8.3.6.1 to extract the eligible cases.

\section{Consent for publication}

Not applicable.

\section{Ethics approval and consent to participate}

Informed consent was obtained from all individual participants included in this study. Since the patient information in the SEER database is deidentified and publicly available, our study was exempt from Institutional Review Board approval. This study was conducted in concordance with the Helsinki Declaration.

\section{Author details}

${ }^{1}$ Department of Radiation Oncology, National Cancer Center/National Clinical Research Center for Cancer/Cancer Hospital, Chinese Academy of Medical Sciences and Peking Union Medical College, Beijing, China. ${ }^{2}$ Department of VIP Medical Services, National Cancer Center/National Clinical Research Center for Cancer/Cancer Hospital, Chinese Academy of Medical Sciences and Peking Union Medical College, Beijing, China.

\section{References}

1. Hancock SL, Tucker MA, Hoppe RT: Factors affecting late mortality from heart disease after treatment of Hodgkin's disease. Jama 1993; 270:1949-1955.

2. van Nimwegen FA, Ntentas G, Darby SC, Schaapveld M, Hauptmann M, Lugtenburg PJ et al: Risk of heart failure in survivors of Hodgkin lymphoma: effects of cardiac exposure to radiation and 
anthracyclines. Blood 2017; 129:2257-2265.

3. McGale P, Darby SC, Hall P, Adolfsson J, Bengtsson NO, Bennet AM et al: Incidence of heart disease in 35,000 women treated with radiotherapy for breast cancer in Denmark and Sweden. Radiotherapy and oncology : journal of the European Society for Therapeutic Radiology and Oncology 2011; 100:167-175.

4. Darby S, McGale P, Peto R, Granath F, Hall P, Ekbom A: Mortality from cardiovascular disease more than 10 years after radiotherapy for breast cancer: nationwide cohort study of 90000 Swedish women. BMJ (Clinical research ed) 2003; 326:256-257.

5. Henson KE, McGale P, Taylor C, Darby SC: Radiation-related mortality from heart disease and lung cancer more than 20 years after radiotherapy for breast cancer. British journal of cancer 2013; 108:179-182.

6. Hardy D, Liu CC, Cormier JN, Xia R, Du XL: Cardiac toxicity in association with chemotherapy and radiation therapy in a large cohort of older patients with non-small-cell lung cancer. Annals of oncology : official journal of the European Society for Medical Oncology / ESMO 2010; 21:18251833.

7. Schytte T, Hansen O, Stolberg-Rohr T, Brink C: Cardiac toxicity and radiation dose to the heart in definitive treated non-small cell lung cancer. Acta oncologica (Stockholm, Sweden) 2010; 49:10581060.

8. Dess RT, Sun Y, Matuszak MM, Sun G, Soni PD, Bazzi L et al: Cardiac Events After Radiation Therapy: Combined Analysis of Prospective Multicenter Trials for Locally Advanced Non-Small-Cell Lung Cancer. Journal of clinical oncology : official journal of the American Society of Clinical Oncology 2017; 35:1395-1402.

9. Haque W, Verma V, Fakhreddine M, Butler EB, Teh BS, Simone CB, 2nd: Trends in Cardiac Mortality in Patients With Locally Advanced Non-Small Cell Lung Cancer. International journal of radiation oncology, biology, physics 2018; 100:470-477.

10. Wang K, Eblan MJ, Deal AM, Lipner M, Zagar TM, Wang Y et al: Cardiac Toxicity After Radiotherapy for Stage III Non-Small-Cell Lung Cancer: Pooled Analysis of Dose-Escalation Trials Delivering 70 to $90 \mathrm{~Gy}$. Journal of clinical oncology : official journal of the American Society of Clinical Oncology 2017; 35:1387-1394.

11. Network NCC: NCCN Clinical Practice Guidelines in Oncology (NCCN Guidelines ${ }^{\circledR}$ ) Non-Small Cell Lung Cancer, Version 6. 2020 edn; 2020.

12. Fine JP, Gray RJ: A Proportional Hazards Model for the Subdistribution of a Competing Risk. Publications of the American Statal Association 1999; 94:496-509.

13. Lally BE, Zelterman D, Colasanto JM, Haffty BG, Detterbeck FC, Wilson LD: Postoperative radiotherapy for stage II or III non-small-cell lung cancer using the surveillance, epidemiology, and end results database. Journal of clinical oncology : official journal of the American Society of Clinical Oncology 2006; 24:2998-3006. 
14. Dai H, Hui Z, Ji W, Liang J, Lu J, Ou G et al: Postoperative radiotherapy for resected pathological stage IIIA-N2 non-small cell lung cancer: a retrospective study of 221 cases from a single institution. The oncologist 2011; 16:641-650.

15. Patel SH, Ma Y, Wernicke AG, Nori D, Chao KS, Parashar B: Evidence supporting contemporary postoperative radiation therapy (PORT) using linear accelerators in N2 lung cancer. Lung cancer (Amsterdam, Netherlands) 2014; 84:156-160.

16. Stewart LA: Postoperative radiotherapy in non-small-cell lung cancer: systematic review and metaanalysis of individual patient data from nine randomised controlled trials. PORT Meta-analysis Trialists Group. Lancet (London, England) 1998; 352:257-263.

17. Hui Z, Men Y, Hu C, Zhou Z, Liang J, Feng Q et al: OA12. 06 A Prospective Randomized Phase $\triangle$ Study of Precise PORT for Patients with p\A-N2 NSCLC After Complete Resection and Adjuvant Chemotherapy. Journal of Thoracic Oncology 2019; 14:S238-S239.

18. Le Pechoux C, Pourel N, Barlesi F, Faivre-Finn C, Lerouge D, Zalcman G et al: LBA3_PR An international randomized trial, comparing post-operative conformal radiotherapy (PORT) to no PORT, in patients with completely resected non-small cell lung cancer (NSCLC) and mediastinal N2 involvement: Primary end-point analysis of LungART (IFCT-0503, UK NCRI, SAKK) NCT00410683. Annals of Oncology 2020; 31:S1178.

19. Dautzenberg B, Arriagada R, Chammard AB, Jarema A, Mezzetti M, Mattson $K$ et al: A controlled study of postoperative radiotherapy for patients with completely resected nonsmall cell lung carcinoma. Groupe d'Etude et de Traitement des Cancers Bronchiques. Cancer 1999; 86:265-273.

20. Lally BE, Detterbeck FC, Geiger AM, Thomas CR, Jr., Machtay M, Miller AA et al: The risk of death from heart disease in patients with nonsmall cell lung cancer who receive postoperative radiotherapy: analysis of the Surveillance, Epidemiology, and End Results database. Cancer 2007; 110:911-917.

21. Douillard JY, Rosell R, De Lena M, Riggi M, Hurteloup P, Mahe MA: Impact of postoperative radiation therapy on survival in patients with complete resection and stage I, II, or IIIA non-small-cell lung cancer treated with adjuvant chemotherapy: the adjuvant Navelbine International Trialist Association (ANITA) Randomized Trial. International journal of radiation oncology, biology, physics 2008; 72:695701.

22. Munro AJ: What now for postoperative radiotherapy for lung cancer? Lancet (London, England) 1998; 352:250-251.

23. Bogart JA, Aronowitz JN: Localized non-small cell lung cancer: adjuvant radiotherapy in the era of effective systemic therapy. Clinical cancer research : an official journal of the American Association for Cancer Research 2005; 11:5004s-5010s.

24. Sawyer TE, Bonner JA, Gould PM, Foote RL, Deschamps C, Trastek VF et al: The impact of surgical adjuvant thoracic radiation therapy for patients with nonsmall cell lung carcinoma with ipsilateral mediastinal lymph node involvement. Cancer 1997; 80:1399-1408. 
25. Keller SM, Adak S, Wagner H, Herskovic A, Komaki R, Brooks BJ et al: A randomized trial of postoperative adjuvant therapy in patients with completely resected stage II or IIIA non-small-cell lung cancer. Eastern Cooperative Oncology Group. The New England journal of medicine 2000; 343:1217-1222.

26. von Lieven H, Burkhardt E: Postoperative radiotherapy of NSCLC-outcome after 3-D treatment planning. Strahlentherapie und Onkologie : Organ der Deutschen Rontgengesellschaft [et al] 2001; 177:302-306.

27. Machtay M, Lee JH, Shrager JB, Kaiser LR, Glatstein E: Risk of death from intercurrent disease is not excessively increased by modern postoperative radiotherapy for high-risk resected non-small-cell lung carcinoma. Journal of clinical oncology : official journal of the American Society of Clinical Oncology 2001; 19:3912-3917.

28. Ichinose $\mathrm{Y}$, Kato $\mathrm{H}$, Koike T, Tsuchiya R, Fujisawa T, Shimizu N et al: Overall survival and local recurrence of 406 completely resected stage Illa-N2 non-small cell lung cancer patients: questionnaire survey of the Japan Clinical Oncology Group to plan for clinical trials. Lung cancer (Amsterdam, Netherlands) 2001; 34:29-36.

29. Feng W, Zhang Q, Fu XL, Cai XW, Zhu ZF, Yang HJ et al: The emerging outcome of postoperative radiotherapy for stage IIIA(N2) non-small cell lung cancer patients: based on the three-dimensional conformal radiotherapy technique and institutional standard clinical target volume. BMC cancer $2015 ; 15: 348$.

30. Kepka L, Bujko K, Orlowski TM, Jagiello R, Salata A, Matecka-Nowak M et al: Cardiopulmonary morbidity and quality of life in non-small cell lung cancer patients treated with or without postoperative radiotherapy. Radiotherapy and oncology : journal of the European Society for Therapeutic Radiology and Oncology 2011; 98:238-243.

31. Curigliano G, Cardinale D, Suter T, Plataniotis G, de Azambuja E, Sandri MT et al: Cardiovascular toxicity induced by chemotherapy, targeted agents and radiotherapy: ESMO Clinical Practice Guidelines. Annals of oncology : official journal of the European Society for Medical Oncology / ESMO 2012; 23 Suppl 7:vii155-166.

32. Armenian SH, Lacchetti C, Barac A, Carver J, Constine LS, Denduluri N et al: Prevention and Monitoring of Cardiac Dysfunction in Survivors of Adult Cancers: American Society of Clinical Oncology Clinical Practice Guideline. Journal of clinical oncology : official journal of the American Society of Clinical Oncology 2017; 35:893-911.

33. Verma V, Fakhreddine MH, Haque W, Butler EB, Teh BS, Simone CB, 2nd: Cardiac mortality in limitedstage small cell lung cancer. Radiotherapy and oncology : journal of the European Society for Therapeutic Radiology and Oncology 2018; 128:492-497.

34. Billiet C, Decaluwe H, Peeters S, Vansteenkiste J, Dooms C, Haustermans K et al: Modern postoperative radiotherapy for stage III non-small cell lung cancer may improve local control and survival: a meta-analysis. Radiotherapy and oncology : journal of the European Society for Therapeutic Radiology and Oncology 2014; 110:3-8. 
Figures

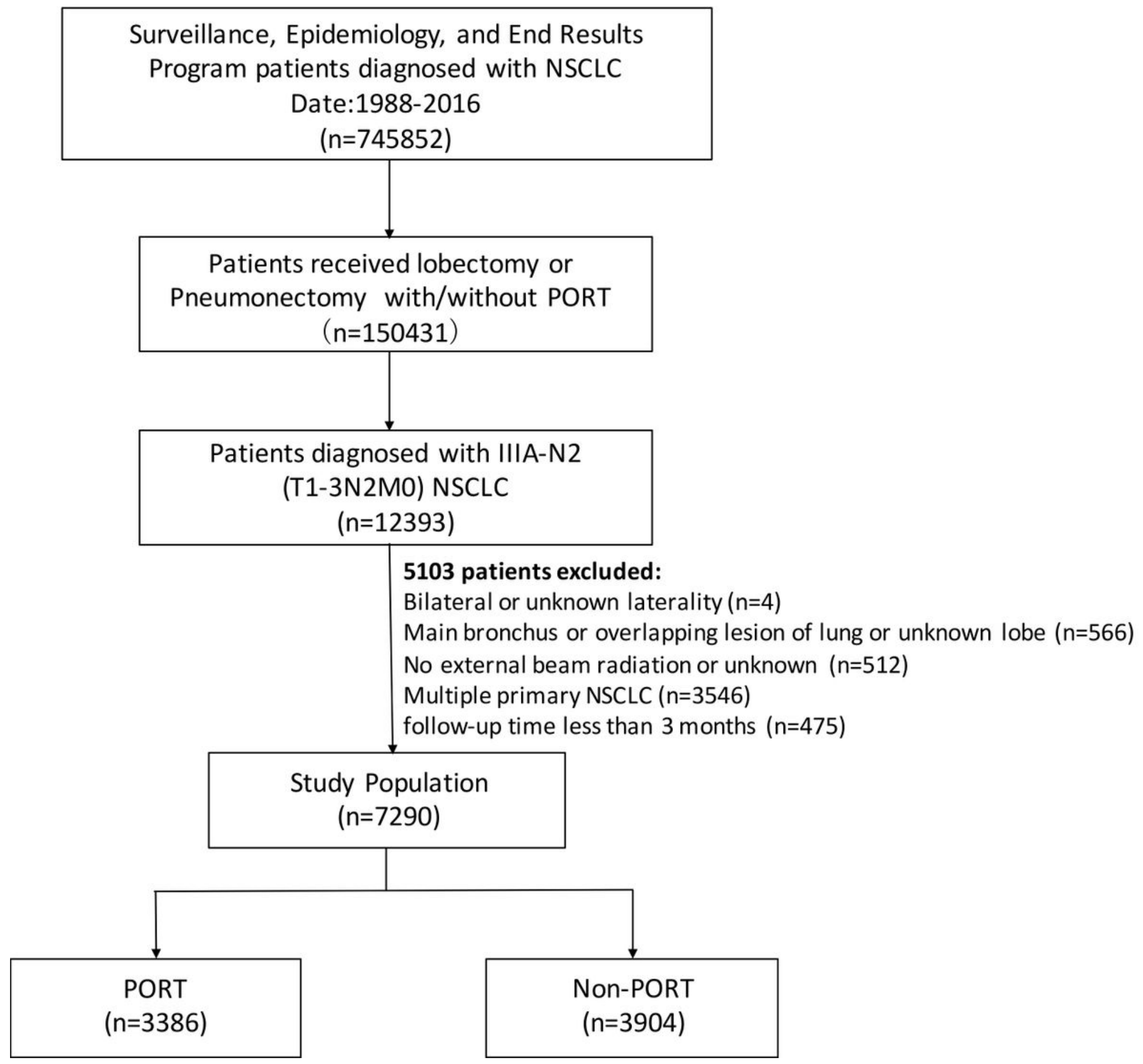

Figure 1

Patients selection diagram 

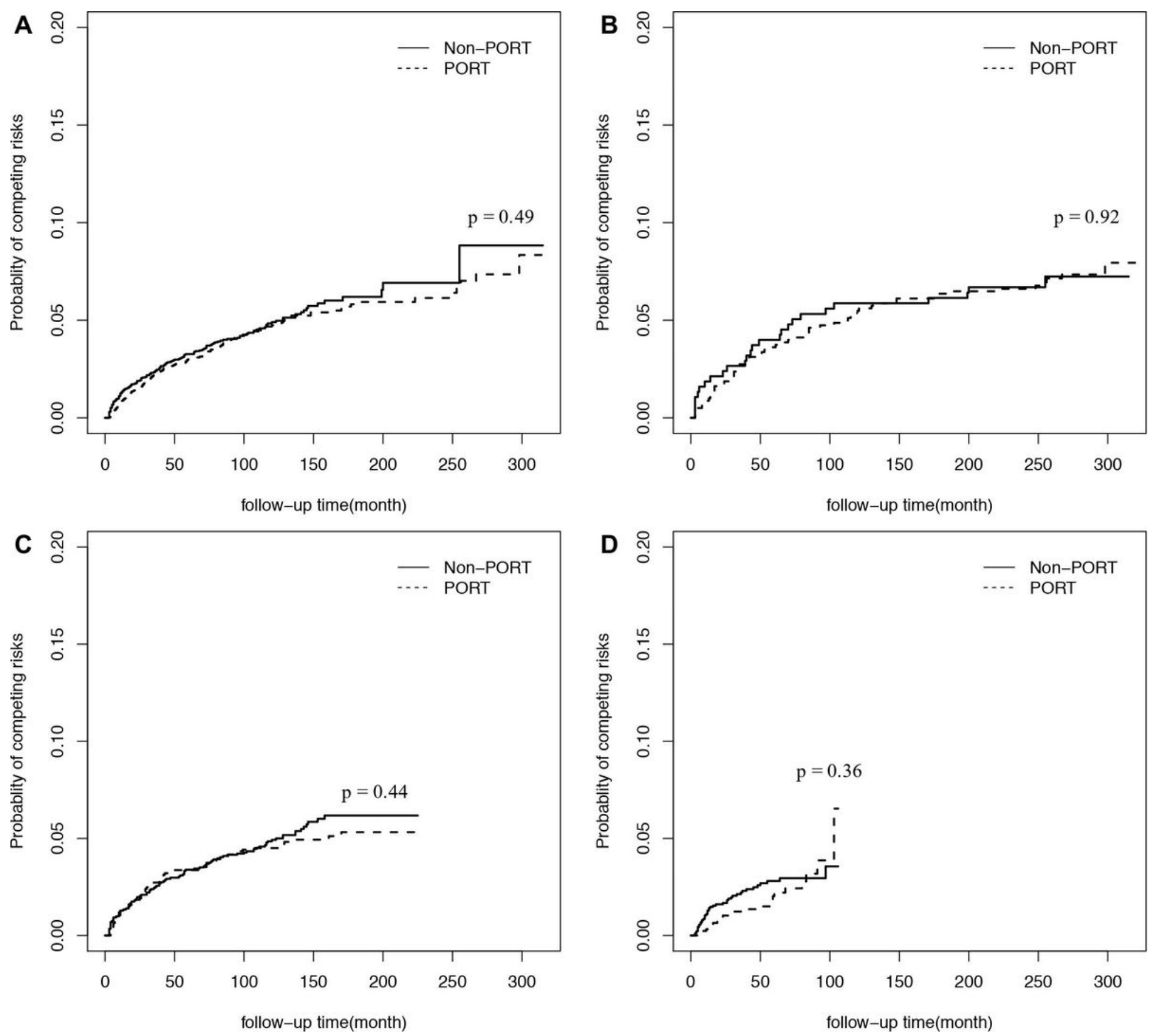

Figure 2

Cumulative incidence of cardiac-related mortality curves by PORT use for: (A) all patients; (B) patients diagnosed from 1988-1997; (C) patients diagnosed from 1998-2007; (D) patients diagnosed from 20082016. 